\title{
UROGYNAECOLOGY AND YOU
}

\author{
A Handbook for Women with
}

Bladder Disorders, Womb and Vaginal Prolapse 
This page intentionally left blank 


\title{
UROGYNAECOLOGY AND YOU
}

A Handbook for Women with

Bladder Disorders, Womb and Vaginal Prolapse

\author{
Han How Chuan $\propto$ Lee Lih Charn \\ Arthur L A Tseng $\boldsymbol{\infty}$ Wong Heng Fok \\ KK Women's \& Children's Hospital, Singapore
}

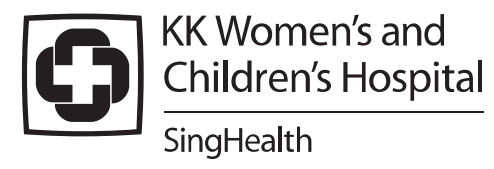


Published by

World Scientific Publishing Co. Pte. Ltd.

5 Toh Tuck Link, Singapore 596224

USA office: 27 Warren Street, Suite 401-402, Hackensack, NJ 07601

UK office: 57 Shelton Street, Covent Garden, London WC2H 9HE

\section{Library of Congress Cataloging-in-Publication Data}

Urogynaecology and you : a handbook for women with bladder disorders, womb and vaginal Prolapse / How Chuan Han ... [et al.].

p. ; cm.

Includes index.

ISBN-13: 978-9814277907 (pbk. : alk. paper)

ISBN-10: 9814277908 (pbk. : alk. paper)

1. Genitourinary organs--Diseases--Diagnosis. 2. Urogynecology. I. Han, How Chuan.

[DNLM: 1. Female Urogenital Diseases--diagnosis. 2. Female Urogenital Diseases--therapy.

3. Urogenital System. WJ 190 U782 2010]

RG484.U766 2010

616.6--dc22

2009027156

\section{British Library Cataloguing-in-Publication Data}

A catalogue record for this book is available from the British Library.

Copyright $\odot 2010$ by World Scientific Publishing Co. Pte. Ltd. and

KK Women's and Children's Hospital Pte. Ltd.

All rights reserved. This book, or parts thereof, may not be reproduced in any form or by any means, electronic or mechanical, including photocopying, recording or any information storage and retrieval system now known or to be invented, without written permission from the Publisher.

For photocopying of material in this volume, please pay a copying fee through the Copyright Clearance Center, Inc., 222 Rosewood Drive, Danvers, MA 01923, USA. In this case permission to photocopy is not required from the publisher.

Printed in Singapore. 
To our loved ones, friends and colleagues who support and inspire us to greater heights. 
This page intentionally left blank 


\section{Preface}

At the beginning of our journey, on 1st April 1990, Kandang Kerbau Hospital $(\mathrm{KKH})$ planted the seed with the start of urogynaecological services. Over the years, this has grown into the present Department of Urogynaecology — a full-fledged and independent department.

Our passion has been to do our very best for our patients, in treating problems like recurrent urinary tract infections, overactive bladder syndrome, stress urinary incontinence, pelvic organ prolapse, painful bladder syndrome, and other urogynaecological problems. To this extent, we have seen our patient numbers increased from a few hundreds in 1990 to more than 12,000 as of 2009 .

Advancement in science and medical technology, coupled with improved awareness has resulted in a greater willingness to inquire and explore issues. No longer are patients willing to accept that they must take a prescribed drug to control their problem, or have a particular surgery to cure their medical condition. Modern society has equipped patients with enquiring minds that ask: "Why do I need this medicine, or this particular surgery?" Patients want to be informed on the likelihood of success or improvement for the treatment or surgery they are recommended to take or undergo, and 
whether there are any complications or side effects. It is with this in mind that we have set out to publish a book that addresses these questions.

We hope that this easy-to-use, concise, yet informative book will help patients understand the common urogynaecological conditions and highlight to them the possible treatment options.

We are truly grateful to all the contributors of this book especially Dr LC Lee and Dr Arthur Tseng who spent much time and effort researching and writing the chapters. We would also like to thank our spouses and families for their support and understanding enabling us to focus in the preparation of this book.

We sincerely thank World Scientific Publishing Co. Ltd. and KK Women's \& Children's Hospital for their support during the long process of producing this book and Ms Judy Wong for her dedication and help in liaising between all parties to make this book a reality.

To all our patients who have passed through our doors, and left with a better quality of life and happier hearts, we hereby express our deepest gratitude, appreciation and thanks for your loyal patronage.

We wish you and your family the very best of health always!

Adjunct A/Prof. William Han How Chuan Head and Senior Consultant Department of Urogynaecology KK Women's and Children's Hospital 


\section{About the Authors}

A/Prof Han How Chuan is a brilliant doctor and surgeon who has pioneered many innovative urogynaecological procedures such as Tensionfree Vaginal Tape (TVT), Tension-free Vaginal Tape - Transobturator (TVT-O), and Prolift System in Singapore. He is also a tireless leader who heads the Department of Urogynaecology

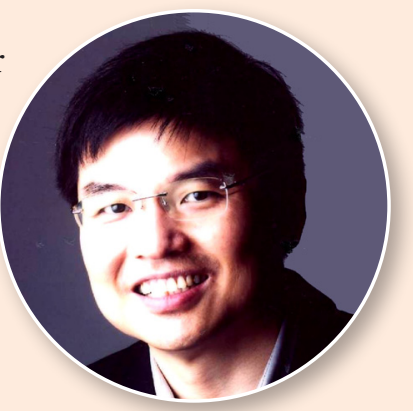
since 1999. Under his leadership, the Department has flourished in leaps and bounds and the KK Urogynaecology Centre (the first Urogynaecology Centre in the Asia Pacific region) opened its doors on 28 November 2001. A/Prof Han received urogynaecology subspecialty training at St. George's Hospital, United Kingdom in December 1996. He has lectured and published extensively on many urogynaecological conditions. A/Prof Han is a clinical senior lecturer with the NUS Yong Loo Lin School of Medicine and Adjunct Associate Professor of the Duke-NUS Graduate Medical School since August 2008. He is presently Chairman, Section of Urogynaecology, College of Obstetricians \& Gynaecologists. 
Dr Arthur Tseng is a consultant obstetrician and gynaecologist at KK Women's \& Children's Hospital, and has been working there since 1997. Dr Tseng graduated in 1996 from Sheffield University and completed his postgraduate studies in 2002. He received further subspecialty training under Professor Linda Cardozo at King's College Hospital, London in 2006. He is actively involved in teaching the Yong Yoo Lin undergraduate medical students and the Duke-NUS postgraduate medical students. Dr Tseng is a frequent contributor of newspaper articles pertaining to women's health issues. He is frequently invited to speak at public forums on urogynaecological issues. Dr Tseng also serves as Honorary Treasurer of The Obstetrical \& Gynaecological Society of Singapore and is regarded as an expert in his field by his peers.

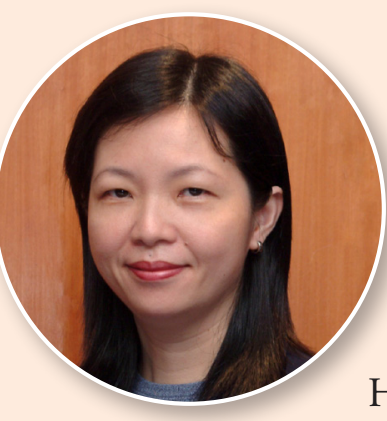

Dr Lee Lih Charn is a senior consultant obstetrician and gynaecologist who has worked in KK Women's \& Children's Hospital since 1994. She is Head of the Ambulatory and Urodynamics Unit, Department of Urogynaecology. Dr Lee underwent subspecialty training in urogynaecology at St. Vincent's Hospital, Sydney, Australia, in 2000. Her special interests are in patients with urinary incontinence and painful bladder syndrome. Dr Lee has been a clinical senior lecturer with the NUS Yong Loo Lin School of Medicine and Adjunct Assistant Professor of the Duke-NUS Graduate Medical School since August 2008. She has contributed numerous articles to local and international journals on urogynaecology. 
Dr Wong Heng Fok is an associate consultant, obstetrician and gynaecologist in KK Women's \& Children's Hospital. He has his subspecialty training in urogynaecology at the Royal Women's Hospital, Melbourne, Australia. He has been invited to speak at several public forums and has written articles in international journals on urogynaecology. He is a clinical tutor with the Duke-NUS Graduate Medical School since 2006 and an Adjunct Instructor of the DukeNUS Graduate Medical School since August 2008. 
This page intentionally left blank 


\section{List of \\ Contributors}

\section{Principal Authors}

Adj. A/Prof Han How Chuan

Senior Consultant

Obstetrician \& Gynaecologist

Head, Urogynaecology Surgery Unit

Head, Department of Urogynaecology

KK Women's \& Children's Hospital

Dr Arthur Tseng

Consultant

Obstetrician \& Gynaecologist

Department of Urogynaecology

KK Women's \& Children's Hospital

Dr Lee Lih Charn

Senior Consultant

Obstetrician \& Gynaecologist

Department of Urogynaecology

Head, Ambulatory Care \& Urodynamics Unit

KK Women's \& Children's Hospital 
Dr Wong Heng Fok

Associate Consultant

Obstetrician \& Gynaecologist

Department of Urogynaecology

KK Women's \& Children's Hospital

\section{Chapter Contributors:}

Dr Natalie Chua Weilyn

Medical Officer

Division of Obstetrics \& Gynaecology

KK Women's \& Children's Hospital

Dr Thanapan Choobun

Clinical Fellow

Department of Urogynaecology

KK Women's \& Children's Hospital

Dr Fernandi Moegni

Clinic Fellow

Department of Urogynaecology

KK Women's \& Children’s Hospital

Dr Arlene Liao

Clnical Fellow

Department of Urogynaecology

KK Women's \& Children’s Hospital 


\section{Contents}

Preface vii

About the Authors ix

List of Contributors xiii

1. Introduction to Urogynaecology 1

2. Female Pelvic and Urinary Tract Anatomy 3

3. An Overview of Urogynaecological Conditions 7

4. Diagnostic Tests and Investigations Used 9 in Urogynaecology and Urodynamics Studies

5. Pelvic Organ Prolapse 17

6. Urinary Incontinence 39

7. Stress Urinary Incontinence 45

8. Frequency-Urgency Syndrome or 59 the Overactive Bladder Syndrome

9. Voiding Disorders 75

10. Painful Bladder Syndrome/Interstitial Cystitis 85

11. Urinary Tract Infection and 93 Recurrent Urinary Tract Infection 
12. Haematuria 103

13. Ageing and Urogenital Syndrome 117

14. Urinary Incontinence Aids 125

15. Pelvic Floor Exercises 133

16. Where to Seek Professional Help and Advice? 137

Glossary 141 